\title{
"EU SOU PROFESSOR POR DECISÃO, PORQUE EU GOSTO, PORQUE É MINHA VIDA!" PAIXÃO, IDENTIDADE E FORMAÇÃO NA DOCÊNCIA MASCULINA
}

\author{
"YO SOY PROFESOR POR DECISIÓN, PORQUE YO GUSTO, PORQUE ES MI \\ VIDA!" PASIÓN, IDENTIDAD Y FORMACIÓN EN LA DOCENCIA MASCULINA
"I AM A TEACHER BY DECISION, BECAUSE I LIKE, BECAUSE IT IS MY LIFE!" PASSION, IDENTITY AND TRAINING IN MALE TEACHING

Josiane Peres GONÇALVES ${ }^{1}$

\begin{abstract}
RESUMO: Este estudo versa sobre o trabalho de professores homens que escolheram o magistério como principal profissão e tem por finalidade identificar o perfil profissional ou características relevantes desses professores para o bom desempenho da função docente. A pesquisa, de natureza qualitativa, foi realizada por meio de gravação de entrevistas com cinco docentes do gênero masculino paranaenses, cujos principais resultados indicam que: todos os professores demonstravam paixão pela profissão escolhida; eles conseguiram construir uma identidade profissional própria, a ponto de desenvolver as suas atividades da maneira particular, e investiam sempre em sua formação profissional. Tais dados sugerem que é importante gostar do que faz, ser sujeito da construção identitária e se manter atualizado, mediante o processo de formação profissional, a fim de que seja possível desempenhar com qualidade a função docente.
\end{abstract}

PALAVRAS-CHAVE: Docência. Identidade. Formação profissional.

RESUMEN: Este es el verso sobre el trabajo de los profesores homens que el maestro o el magisterio principal como el tiempo y la función de identificar y el perfil de los profesionales de las personas más importantes. Una pesquisa, de la naturaleza cualitativa, realizada por mi parte de las entrevistas con cinco docentes del hombre masculino paranaense, los principales resultados son indicadores de todos: los profesores demonstravam paixão pela profissão escolhida, eles gachichy uma eu professional profprional, a ponto de atvolver como suas atividades da maneira particular e investiam semper em sua formacion profesional. El plan es una forma importante de entenderlo, mediante un proceso de formación profesional, una imagen de la posibilidad de un futuro profesional o una empresa docente.

PALABRAS CLAVE: Enseñanza. Identidad. Formación profesional.

ABSTRACT: This study deals with the work of male teachers who chose the teaching profession as their main profession and aims to identify the professional profile or relevant characteristics of these teachers for the good performance of the teaching function. The qualitative research was carried out by recording interviews with five male teachers from Paraná, whose main results indicate that: all teachers showed a passion for the chosen

${ }^{1}$ Universidade Federal de Mato Grosso do Sul (UFMS), Naviraí - MS - Brasil. Professora de Pós-Graduação da FAED/UFMS e CPAN/UFMS. ORCID: http://orcid.org/0000-0002-7005-849X. E-mail: josiane.peres@ufms.br

RIAEE - Revista Ibero-Americana de Estudos em Educação, Araraquara, v. 15, n. 3, p. 1221-1235, jul./set. 2020. e-ISSN: 1982-5587. 
profession, they were able to build a professional identity of their own, to the point of developing their activities in the private way and always invested in their professional training. Such data suggest that it is important to like what it does, to be a subject of identity construction and to keep up to date, through the process of professional training, so that it is possible to perform with quality the teaching function.

KEYWORDS: Teaching. Identity. Professional qualification.

\section{Introdução}

Tendo em vista que o magistério é visto como formação feminina, conforme Gonçalves (2009) e Louro (2012), não se observa um grande número de homens atuando como docente, principalmente nas fases iniciais da educação básica. Contudo, existem alguns homens que escolheram a área da educação como principal profissão e desenvolveram um percurso profissional que incluiu várias etapas da educação básica e também o ensino superior. Assim, surgiu o interesse em entender o perfil desses professores, uma vez que eles são minoria na área da educação.

É importante destacar que a área da educação possui algumas especificidades, diferentes de outras áreas de atuação. Assim, Tardif (2002) destaca que, no exercício da função docente, o professor traz em si mesmo as marcas do seu trabalho e, apesar de desempenhar um papel fundamental no processo educativo, ele é produzido e modelado pelo trabalho. Trata-se de uma função multidimensional que incorpora elementos relativos à identidade pessoal e profissional do professor ao seu trabalho diário no contexto escolar.

O referido autor também analisa a complexidade da profissão docente ao comparar o trabalho realizado pelos professores com aquele que é desenvolvido nas indústrias. Ele diz que, ao contrário do operário que trabalha com matérias-primas que são transformadas rapidamente, cujo resultado final pode ser visto num curto espaço de tempo, o professor atua com pessoas de culturas diferenciadas e o resultado do seu trabalho pode ser visto somente no longo prazo; na indústria, os objetos manipulados são homogêneos e passivos, permitindo ao trabalhador ter o controle direto sobre o produto; na educação, o professor trabalha com pessoas heterogêneas e ativas, necessita sempre da colaboração do "objeto" e nunca tem o controle total sobre os seus alunos; o produto final do trabalho é, no caso da indústria, material, podendo ser observado, medido e avaliado, cujo consumo é totalmente separável ou independente da atividade do trabalhador; no caso do professor, o produto final do trabalho é intangível e imaterial, pode ser dificilmente observado ou medido e o consumo pode ser 
dificilmente separado da atividade e do espaço de trabalho, sendo, portanto, dependente do trabalhador (TARDIF, 2002).

Essa imaterialidade que marca o produto final do trabalho docente, de certa forma se relaciona com o que ocorre com o próprio profissional da educação, ou seja, o fato de trabalhar com pessoas que têm opiniões próprias e sujeitos de seu processo de formação faz com que o professor também se transforme e construa o seu conhecimento enquanto exerce a função docente. Ao refletir sobre a subjetividade dos professores, Braga, Ferreira e Gonçalves (2018, p. 43) enfatizam que o próprio conhecimento do educador "[...] é tecido a cada formação que recebem ou que adquirem ao longo da sua vida, pela (re)interpretação do vivido, que se dá por diferentes marcas de autoria e registros pessoais”. Nesse sentido, “[...] o indivíduo passa a compreender o seu processo de formação, tornando-se um sujeito reflexivo e crítico de suas próprias atitudes e do seu desenvolvimento, procurando saber sobre si mesmo e suas ações no decorrer da sua existência" (p. 44).

As relações estabelecidas com os alunos, no exercício do trabalho docente, contribuem para a construção da identidade dos professores, devido às trocas de experiência plurais existentes em sala de aula, como enfatiza Bragança (2011, p. 161):

A socialização liga, assim, o sujeito aos diferentes contextos dos quais faz parte, implicando integração e adaptação ao sistema. Considerando que o social é permeado de contradições e dualidades, também a identidade do sujeito não é harmoniosa, mas aponta para uma constante busca de equilíbrio entre processos plurais, estando em permanente reconstrução.

A busca por um equilíbrio no processo de construção da identidade docente está relacionada com a diversidade de ideias e pensamentos predominante no espaço educativo, mas também à maneira pela qual os sujeitos interpretam as vivências. De acordo com Veiga (2012), por meio das relações estabelecidas em âmbito escolar, o profissional da educação "[...] confere o seu trabalho, definindo o que quer, e o que não quer, e o que pode como professor" (p. 28).

Essas trocas de experiência no contexto educativo são importantes por exercerem influências tanto na vida dos alunos quanto dos professores. Dessa forma, essa pesquisa, que aborda o trabalho de professores homens que escolheram o magistério como principal profissão, tem por finalidade identificar o perfil profissional ou características relevantes desses professores para o bom desempenho da função docente. 


\section{Metodologia}

A realização da investigação, de natureza qualitativa, se deu por meio de pesquisa bibliográfica e de campo. Ao priorizar a pesquisa qualitativa, destaca-se que se trata de uma ação intencional, em que se valoriza os motivos e razões dos participantes que dão sentido aos seus anseios, crenças, valores e atitudes, tendo em vista suas interações sociais (FRASER; GONDIN, 2004).

Para o processo de coleta de dados, foi feita a opção pela gravação de entrevistas individualizadas, a partir de um roteiro previamente elaborado, que, segundo Duarte (2004), ao gravar as entrevistas é preciso extrair o que é subjetivo e pessoal dos sujeitos, para que seja possível perceber a dimensão do grupo social em que o indivíduo encontra-se inserido.

Os participantes da pesquisa eram todos do gênero masculino, eles escolheram o magistério como principal profissão, todos tinham experiência como docentes na educação básica e ensino superior e residiam em municípios do interior do estado do Paraná. A fim de preservar as identidades dos participantes, para este estudo foram utilizados nomes fictícios iniciados pelas cinco vogais, tais como: Adão: 43 anos, casado, dois filhos, graduado em Filosofia; Elias: 38 anos, casado, dois filhos, graduado em Filosofia, Mestrado em Ciências Sociais Aplicadas; Ivan: 45 anos, casado, três filhos, graduado em Matemática, Mestrado em Ciências e Engenharia da Produção; Oscar: 59 anos, casado, dois filhos, graduado em Filosofia, Mestrado em Educação; Urias: 64 anos, casado, dois filhos, graduado em Pedagogia, Mestrado em Educação, Doutorado em Ciências Empresariais na Argentina.

Após a finalização da coleta de dados, foram feitas as transcrições das entrevistas e sistematização dos dados, cujas análises e discussões foram organizadas a partir das seguintes temáticas: Paixão pela profissão docente; Construção de identidade profissional própria; Investimento em formação profissional; conforme apresentados na sequência.

\section{Paixão pela profissão docente}

Para iniciar esta abordagem relativa ao gostar do que se faz, destaca-se o relato do professor Urias que, sem conseguir esconder suas emoções, ressalta: "Sou uma pessoa muito realizada, muito feliz, muito satisfeita com aquilo que a educação nos ensinou e acredito que o grande mérito é hoje nós termos consciência de que a educação nos fez mais pessoa, mais cidadão!”. Ele também faz a seguinte reflexão sobre a sua carreira profissional: 
Eu me considero bem-sucedido em todos os aspectos. Primeiro como realização profissional. Eu não me veria realizado em outra profissão. Se eu tivesse me aposentado e partido para outra alternativa talvez eu não me sentisse à vontade, principalmente porque algo que eu sempre digo é que precisa gostar daquilo que faz. (Urias).

Fica evidente que o professor, mesmo aposentado, optou por continuar na área da educação, por sentir-se realizado ao atuar como professor. Situação semelhante foi relatada por Oscar: "Eu sou professor por decisão, porque eu gosto, porque é minha vida!". O fato de deixar de ser professor seria uma perda inestimável, segundo o referido professor, e deste modo a opção por continuar é uma forma de manter viva a própria juventude. "Então eu não sei, às vezes a gente brinca, tanto eu como a esposa, de quando a gente vai parar, e eu acho que parar é perder a vida. A gente sente hoje a necessidade de estar no meio da juventude, de estar enfrentando desafios...”.

Realmente o casal não evidencia a idade que tem, representa ser mais jovem se comparado com pessoas da mesma faixa etária e talvez a explicação para tal diferença está exatamente em conviver com pessoas mais jovens e atuar numa área em que se sentem realizados como pessoa e como profissional. "No meu trabalho eu primeiro considero o lado profissional, a realização, gostar daquilo que está fazendo. Por isso eu continuo fazendo a mesma coisa e não consigo me ver fora da atividade" (Oscar).

Os demais professores entrevistados também deixaram claro que gostam muito do que fazem e que isto é fundamental para prosseguir na carreira do magistério. Desta forma, Ivan relatou: "Nada seria tão significativo para minha vida como a carreira de professor!". Ele se sente especialmente realizado quando sabe que o seu trabalho exerce algum tipo de impacto na vida dos alunos. Assim ele exemplifica: "Você sair na rua e o aluno gritar 'Professor Ivan, tudo bem?'. Ele recordar, lembrar de mim... Aquele aluno que era lá da $6^{\mathrm{a}}$ série, do ano de 96...”. Segundo o professor, é gratificante saber que, depois de tanto tempo, o aluno se aproxima e diz: "Hoje eu estou fazendo uma faculdade de Matemática e estou me espelhando exatamente em suas aulas!". Ou outro que disse: "Eu passei num concurso e estou procurando dar aulas exatamente igual você dava para mim...".

Tais exemplos evidenciam o que é dito por Gusdorf (2003), que todo encontro nos desloca e nos recompõe, não havendo, portanto, momentos neutros. Ou seja, o tempo passa, mas o que foi importante para o aluno ele não esquece e continua tendo os professores marcantes como referência a ser seguida. Está aí uma das importâncias do trabalho do professor, que é influenciar a vida dos seus alunos, não somente na sala de aula, mas ao longo da sua vida profissional. 
Adão também fez referência a gostar da profissão ao dizer que considera que teve uma carreira bem-sucedida e afirma que: "O seu sucesso é uma pessoa estar no meio que ela quer e não no meio forçado.”. Ou seja, todo profissional passa muito tempo no ambiente de trabalho, e se estiver num "meio forçado", ou não se sentir bem com o desempenho da própria função, as consequências podem ser negativas tanto para o próprio profissional, neste caso o professor, quanto para as pessoas que fazem parte do mesmo processo, especialmente os alunos.

Um caso que chamou a atenção foi Elias, por evidenciar que gosta do que faz: "Algo que no meu ponto de vista encanta é educar. De certa maneira enobrece.”. Mas ao mesmo tempo sofre quando observa algumas incoerências no meio educacional: "Eu sou um declarado apaixonado pela Ciência, mas sou muito sofredor na construção, porque ao defender a Ciência eu me deparo com outro tipo de exigência que é o canudo.”. Ele também demonstrou se sentir angustiado com o fator salarial: "Eu tenho boa expectativa do magistério porque eu amo o que faço, no entanto, a renda é uma questão crucial na vida do contexto globalizado...”. Esta questão salarial será discutida num outro momento, especialmente por se tratar de um fator que teve interpretação bastante diferenciada entre os entrevistados. Enquanto alguns diziam que, ao comparar com outras profissões, consideravam que ganhavam bem, outros estavam insatisfeitos com o salário.

De qualquer forma, todos os docentes pesquisados evidenciaram que gostam da profissão do magistério, sendo este um dos principais fatores que, possivelmente, tenham contribuído para que tivessem carreiras bem-sucedidas. E, para finalizar esta temática, retomo a fala de um dos professores, que ressaltou: "Gostaria que você dissesse nas suas aulas que você conhece alguém que admite que o mundo pode ser melhor através da educação e que vale a pena ser professor." (Urias).

\section{Construção de identidade profissional própria}

Esta característica relativa à identidade profissional abrange todos os profissionais da educação e não somente os docentes pesquisados, uma vez que, segundo Tardif (2002), a identidade profissional não é simplesmente um dado, mas também um construto que remete aos atos de agentes ativos capazes de justificar as suas práticas e de dar coerência às suas escolhas. Dessa forma, para compreender a formação da identidade dos professores é preciso inseri-la na história dos próprios atores, das suas ações, dos seus projetos e do seu desenvolvimento profissional. Para o autor, vários fatores (inserção na profissão, choque com 
a realidade, aprendizagem na prática, descoberta dos próprios limites, negociação com os outros, etc.) modelam a sua identidade profissional, que passa a ser exclusiva de cada professor.

Apesar de concordar com as ideias do autor, foi possível observar que alguns deles tinham uma identidade profissional própria, porque, ao se preocuparem primeiramente com as necessidades dos alunos, foram em busca de alternativas que resultaram num estilo próprio de ensinar.

Fazia dez anos que eu estava fora da faculdade, fora de sala de aula, mas o que eu fiz nesse período foi trabalhar com alunos que os pais chamavam para tentar resolver o problema do aluno. Alunos com muita dificuldade... Então trabalhando com esses alunos eu desenvolvi meu método de ensino que eu não sabia que era diferente de sala de aula. (Ivan).

O professor relatou que, após este longo período trabalhando com alunos que apresentavam dificuldade na área de Exatas, ele passou num concurso e começou a dar aula. Logo no início ele começou a utilizar o seu próprio "método" de ensinar: "Estou só relatando o que aconteceu nos primeiros dias, como eu não sabia trabalhar na sala da forma tradicional, eu não sabia trabalhar com aquele estilo, eu decidi fazer do meu jeito.”. É claro que teve problemas porque não seguia o padrão esperado pela escola, e ainda mais por causar outros tipos de situações atípicas no ambiente escolar:

Na primeira reunião pedagógica que eu participei, os professores sabiam tudo dos alunos: eles sabiam quem pulava muro, quem fumava drogas, quem chegava atrasado, quem saía antes, quem não participava das aulas, quem começava o ano e não terminava, mas eles não sabiam como trabalhar com esses alunos. Como eu não conhecia ninguém, comecei a trabalhar do meu jeito, e esses alunos não apresentaram esse tipo de problema. (Ivan).

O professor deixou transparecer um nível elevado de autoestima ao dizer que, nas suas aulas, os alunos tinham um comportamento adequado se comparado com o que era dito pelos outros colegas de trabalho. Consequentemente, esta mudança de atitude por parte dos alunos se refletiu no resultado da aprendizagem:

Os alunos chegavam no início e ficavam até o final das aulas, porque era o meu jeito que estava predominando ali, sem saber que estava fazendo de forma melhor que os demais. Chegou ao ponto dos alunos dentro da Matemática tirar as melhores notas, de forma geral. (Ivan).

Segundo o professor, "Na primeira reunião de Conselho de Classe foi identificado que em Matemática todos estavam bem dentro da minha turma e nas outras disciplinas não.”. 
Diante deste contexto, a coordenação alertou: "Professor, você está motivando muito seus alunos, daí eles não querem estudar outra matéria! Hoje só falam em Matemática!". Ele indagou: “O que eu faço então?”. A coordenação respondeu: “Ah, você vai ter que baixar um pouquinho o seu ritmo...". Ele, com pesar, afirmou que: "Baixando o meu ritmo eu estraguei todas as turmas. Aí eles foram mal em Matemática, Português, História, Geografia, todas as matérias!”.

Por fim, o professor decidiu agir de acordo com o próprio estilo, ou seja, tendo uma identidade profissional própria, que para Braga, Ferreira e Gonçalves (2018, p. 47), “Ao constituir essa identidade, a pessoa passa a ser sujeito das suas próprias ações e vai se transformando ao longo da sua trajetória profissional e social à medida que assume novas identificações". Assim o Professor Ivan enfatizou: "Eu decidi a sempre trabalhar do meu jeito e optei em fazer outro experimento, e a melhor ideia foi aplicada sem ouvir muito o lado pedagógico.”. Vale ressaltar que o professor, quando passou a atuar no ensino superior, teve a oportunidade ou o desafio de ensinar Matemática para um aluno cego. Como não sabia como agir naquela situação, foi em busca de alternativas e acabou por criar “[...] esse material inicialmente era uma placa perfurada em linha e colunas, perpendiculares e tal, pra montar um plano e a gente nem sabia que seria um projeto".

Os comentários sobre o material pedagógico criado pelo professor servem para fundamentar a ideia de que Ivan sempre procurou ter uma identidade própria no seu trabalho pedagógico, resultando em uma contribuição social importante e no reconhecimento por parte da sociedade:

No início eu me sentia o pior professor para um aluno cego, isso aconteceu em 98. Em 98 eu era o pior que eu possa imaginar, não sabia nem falar... No final do ano 2000 eu já estava como os melhores professores para atuar com o cego, e hoje as pessoas me classificam como um dos melhores para atuar de forma geral dentro da Matemática. Eu não sou de trabalhar com a Matemática aquela operação simbólica, eu quero dar significado ao aprendizado do aluno, então essa diferença faz com que as pessoas sintam motivação de estudar Matemática... (Ivan).

Toda esta trajetória foi marcada pelo desenvolvimento de atividades que o professor considerava como sendo mais corretas para determinados tipo de aluno. Tal atitude reflete tanto o estilo da sua identidade profissional quanto sua autoestima elevada, sendo esta última caracterizada pela percepção de que é considerado um dos melhores do país na sua área de atuação. De acordo com Mosquera e Stobäus (2006), a autoestima é entendida como o conjunto de atitudes que cada pessoa tem sobre si mesma, que resulta da percepção avaliativa 
sobre a própria pessoa. Assim, o professor Ivan, que tem ganhado diversos prêmios com o seu método de trabalho, não demonstra falsa modéstia ao afirmar que é um dos melhores na área.

Em relação à construção da identidade profissional, o professor Elias disse que inicialmente costuma ser "bastante rigoroso", para que o aluno compreenda que tem responsabilidades a cumprir, mas também procura ser "bastante flexível ao diálogo com o aluno.”. Ele analisa que: "Essa exigência inicialmente não é muito bem aceita pelos alunos, ao longo do semestre ou ano letivo, vai sendo entendido como uma necessidade a eles próprios, eles alunos".

Elias comentou ainda que é muito calmo e muito organizado. Usa agenda para tudo e “essa característica pessoal me dá uma condição também de organização profissional em sala de aula”. Enquanto o referido professor percebe que manter um padrão de rigorosidade, de organização e de flexibilidade na relação estabelecida com o aluno tem resultados positivos, Adão relatou que encontrou outra forma de encaminhar a sua prática, constituindo, assim, a sua identidade profissional.

Dentro da sala de aula você ser uma pessoa totalmente expansiva é conseguir fazer sua aula ficar dinâmica, divertida e séria. Quando eu consegui descobrir isso daí eu tive grande sucesso que foi chegar, dar aula, brincar, fazer uma aula dinâmica, fazer uma aula motivada, fazer o aluno dar risada e ao mesmo tempo puxar ele pro conteúdo bibliográfico e fazer ele produzir. (Elias).

Através de situações de ensino caracterizadas pelo dinamismo, por inovações e por aulas motivadoras, o professor encontrou uma forma de trabalhar o conteúdo através de um clima agradável e que, segundo ele, vem dando muito certo desde que passou a adotar este tipo de procedimento.

É possível notar que, ao longo do tempo, cada professor foi adotando um estilo próprio de ser docente, caracterizando, assim, a própria identidade, mas no caso de quem já percorreu uma longa carreira, se aposentou e continuou atuando no magistério, o que teria a dizer em relação à sua identidade profissional?

Poderíamos afirmar que a identidade ultrapassa a prática educativa ocorrida em sala de aula, para ir além e atingir um padrão mais elevado, caracterizado pelo ser educador e não somente professor. Para Braga, Ferreira e Gonçalves (2018, p. 46), “[...] a identidade se constitui como parte epistemológica na formação do professor, fazendo com que esse processo proporcione aos indivíduos um caminho de reflexão sobre as suas escolhas e atitudes". Os autores também argumentam que a "[...] a construção da identidade profissional faze parte da vida cotidiana do sujeito que trabalha e atua na construção e na formação do 
indivíduo que vai desenvolver seu trabalho na sociedade, que é dinâmico e está sempre se refazendo" (p. 47). Nesse sentido, o professor Urias relata que a satisfação e o desafio de ser educador é a principal marca da sua identidade profissional:

Bom agora eu sempre durmo bem e tenho bons sonhos... Um dos sonhos que nós alimentávamos era de que um dia talvez nós conseguíssemos ser educadores e não somente professores. Talvez nós tivéssemos descoberto esse caminho do saber, do saber fazer, e do saber ser, isso é exercício do profissional do magistério, ser professor implica nisso. Ser educador implica muito mais, então eu sempre alimentei esse sonho de um dia eu ser educador, e hoje eu começo a desvendar esse caminho. (Urias).

Provavelmente é uma grande satisfação chegar a esta consciência e constatação. Chegar ao final de uma carreira, retomá-la de outra forma, agora como empreendedor da área da educação, e sentir que cumpriu a sua função de educador. Na realidade, Urias foi professor ao longo de uma vida e agora começa a "desvendar esse caminho" de ser educador, sendo esta a característica mais marcante da identidade do professor.

\section{Investimento em formação profissional}

Cada vez mais vem se tornando frequente a ideia de que todos os profissionais precisam investir em formação, mas nem sempre é isso que ocorre, especialmente na área de educação. É claro que muitos docentes têm buscado se atualizar devido à exigência da própria legislação ou instituição de ensino, não significando, contudo, que estejam conscientes de que a formação é necessária tanto para o desenvolvimento de um trabalho de qualidade, quanto para o avanço na carreira profissional. Ademais, o processo de formação docente implica na própria construção da identidade docente, como ressaltam Braga, Ferreira e Gonçalves (2018, p. 48, grifos dos autores):

[...] uma formação constituída ao longo do tempo, não sendo congênita desde o começo, mas algo que se sobressai de uma ação que não é completa, mas que está sempre em formação. Não é algo que é determinado apriori, mas uma ação que ocorre a partir do indivíduo que se identifica com determinada escolha, promovendo o seu crescimento profissional.

No caso dos professores entrevistados, foi possível constatar que todos tiveram a preocupação em ampliar a formação e buscaram formas de implementá-las. Adão relatou que: "Em 1996 eu sentia muita dificuldade porque eu tinha novos conceitos que eu ouvia e via mais eu não tinha como elaborar isso. Era uma dificuldade muito grande.”. Resolveu fazer um curso de especialização que o ajudou a entender que não se pode parar nunca. Desta forma, 
fez outros cursos de especialização, pretende fazer outro curso de graduação, por ter a convicção de que: "O que me motiva é a descoberta, é aquela história do 'Só sei que nada sei' e ir em busca disso."

O referido professor disse ainda que, "Dependendo do mês, $15 \%$ a $20 \%$ do que eu ganho, eu procuro investir na minha profissão [...] seja em livro, revista, notebook, internet, seja o que for, ou seja, em qualificação.”. Ao justificar o porquê de agir desta forma, o professor revelou que acredita ser importante investir em si mesmo, na própria pessoa, por ser um tipo de investimento que não se perde, ninguém pode tirar.

De fato, quem faz um curso de especialização, mestrado ou doutorado, além do conhecimento, tem mais oportunidades de avançar na carreira, como foi relatado por Elias: "No momento que eu decidi fazer especialização é que as portas do mercado de trabalho se abriram e no momento que eu entrei no mestrado elas se ampliaram ainda mais.".

O professor Ivan relatou que sempre buscou se atualizar. E foi em um destes eventos de formação continuada, em um "Seminário em Faxinal do Céu”, no estado do Paraná, que, ao ser escolhido entre os seus colegas para apresentar um trabalho aos 800 professores participantes, foi visto por um diretor de uma faculdade particular de Cascavel que, por gostar da sua exposição, o convidou para ser professor de ensino superior: "Um certo dia ele me ligou me oferecendo a oportunidade de trabalhar aqui na faculdade. Então, eu conquistei essa vaga sem me oferecer, sem apresentar o currículo, e sim por me apresentar ao público num curso de formação de professores.

Mais uma vez a formação representou a oportunidade para o avanço na carreira profissional, porque nos ambientes de formação continuada, além de adquirir novos conhecimentos, a pessoa tem a possibilidade de fazer novos contatos e se tornar conhecida entre os profissionais da sua área.

Vale lembrar que cada vez mais vem aumentando o número dos cursos de formação continuada, como congressos, simpósios, seminários, etc., onde se abre a possibilidade para os professores pesquisadores apresentarem o resultado dos seus trabalhos. Neste contexto, ao mesmo tempo em se que aprende com o que foi produzido pelos outros, tem-se a oportunidade de divulgar o próprio conhecimento. Segundo Freire (1997, p. 32), aquele que ensina precisa pesquisar para não ficar apenas reproduzindo o que foi pensado pelos outros:

[...] o que há de pesquisador no professor não é uma qualidade ou forma de ser ou de atuar que se acrescente à de ensinar. Faz parte da natureza da prática docente a indagação, a busca, a pesquisa. $\mathrm{O}$ de que se precisa é que, em sua formação permanente, o professor se perceba e se assuma, porque professor, como pesquisador. 
No que se refere ao ato de pesquisar, embora reconhecendo que o tempo é insuficiente para isso quando se trabalha em faculdade e não universidade, Elias relatou: "Eu venho tendo produções em forma de capítulos de livros, artigos científicos, orientações de artigos acadêmicos de graduação, especialização, participação em bancas e participação em eventos diversos.”. Ivan demonstrou ter grande preocupação com a pesquisa, a ponto de reduzir a sua carga horária na faculdade para investir no seu projeto de Ensino de Matemática Para Cegos, cujos resultados são considerados positivos, já que foi reconhecido pelo MEC e, gradativamente, deverá ser utilizado em todo o país.

Ou seja, investir em formação é necessário e em produção de conhecimento é imprescindível. Para muitos docentes, a realização de pesquisas com maior nível de qualidade acontece através da inserção em programas de mestrado e doutorado. Sabemos que, no Brasil, ainda são poucos os programas existentes se comparados com a quantidade de professores interessados, por isso muitos acabam por não fazer. Uns por dificuldade de deslocamento, outros por não terem condições de encarar a concorrência acirrada ou levar adiante um curso com elevado padrão de exigência.

Uma exceção é Oscar que, sendo mestre em Educação, disse: "Eu só não fui fazer doutorado, não é porque não teria condições de enfrentar um doutorado, é uma opção e perspectiva de vida, qualidade de vida.”. Explicou que, como teve uma longa carreira juntamente com esposa na área do magistério, agora prefere trabalhar num ritmo mais tranquilo e se preocupar com outras coisas importantes para a sua vida e a de sua família, ou seja, busca realmente manter a qualidade de vida. De acordo com Felden Pereira et al., (2014, p. 222), as condições de "[...] qualidade de vida não devem ficar focadas apenas nas questões de saúde física e mental, mas, também, em outras dimensões da vida das pessoas, como trabalho, família e amigos".

Urias também investiu em formação, fez três cursos de especialização e, com muita dificuldade, conseguiu fazer o seu mestrado em Educação na Pontifícia Universidade Católica do Paraná (PUCPR):

Fiz um curso de mestrado de bom nível, inclusive acho de alto nível. Acho que a PUC é hoje uma Universidade de $1^{\circ}$ mundo. Eu acredito que foi para valer mesmo. Então fomos o $1^{\circ}$ dessa turma a defender a dissertação, e me lembro que todos os meus colegas se fizeram presentes nessa $1^{\circ}$ defesa. Então participamos da $1^{\circ}$ turma, fomos o $1^{\circ}$ a defender e até recebemos uma homenagem pública lá no dia. Porque afinal de contas, nós que não morávamos lá em Curitiba, que viajamos todas as semanas, conseguimos elaborar nosso trabalho fomos para banca. Primeiramente fomos classificados e depois defendemos em primeiro lugar, enquanto aqueles que moravam em Curitiba que eram da instituição, ficaram pra trás. (Urias). 
Em seguida foi humilde ao ressaltar: "Eu acredito que não seja nenhum mérito meu não! Eu tive a oportunidade de ter como orientadora uma pessoa fantástica e tivemos uma identificação muito grande com ela...". Aproveitou a oportunidade para reconhecer o trabalho da professora orientadora e homenageá-la: “Acho que muito do mérito de termos nos saído bem e ser os primeiros a defender cabe também a ela. Aqui fica minha homenagem para ela".

Quanto à dificuldade para fazer o doutorado, Urias relatou que "Não podíamos viajar toda semana para São Paulo ou para o Rio ou sei lá para onde, pra fazer um curso de doutorado numa instituição pública que geralmente cobra dedicação exclusiva...”. Acabou por cursar em outro país e na área de Administração de Empresas: “[...] pintou a oportunidade de fazermos o nosso doutorado na Argentina e fomos lá, só que numa outra área...”. Como atuava também em funções administrativas, como coordenador de curso e diretor de faculdade, o curso acabou sendo importante, e principalmente depois que passou a atuar como proprietário de uma instituição de ensino superior privada.

É possível notar a preocupação com a formação e, ao mesmo tempo, a dificuldade para conseguir buscar os seus objetivos, deixando claro que são pessoas com carreiras bemsucedidas não por acaso, mas por haver um grande esforço para poder conquistá-las.

Comenta-se, na cultura popular, que Einstein já dizia que apenas $1 \%$ do que somos é inteligência e $99 \%$ é suor. Se esta ideia é verdadeira ou não é difícil afirmar, mas ao relacionála com o perfil dos professores entrevistados é possível inferir que, por mais que eles tenham a capacidade, a pré-disposição ou a inteligência para serem bons professores, o peso maior pode ser atribuído ao esforço que dedicam para se capacitar e realizar bem o seu trabalho, sendo sujeitos de todo o processo.

\section{Considerações finais}

Com a realização da pesquisa com cinco professores paranaenses foi possível notar que existiam algumas características que eram comuns e marcaram o perfil dos participantes, tais como: eles demonstravam verdadeira paixão pela profissão escolhida, sentiam prazer em poder ensinar, se relacionar com os alunos e, acima de tudo, se sentiam motivados ao perceber o resultado do seu trabalho; os professores também foram sujeitos no processo de construção de uma identidade profissional e essa conquista foi considerada importante para que eles desempenhassem as atividades docentes de acordo com as suas especificidades, ou características pessoais; os cinco homens professores procuravam sempre investir na sua 
formação profissional, por entender que deveriam se qualificar, a fim de atender as novas demandas da prática educativa.

Diante do estudo realizado, destaca-se que por ficar muito tempo no ambiente de trabalho, é importante que os profissionais da educação gostem da função desempenhada, para que a realizem com dedicação e se sintam realizados por contribuir com a formação de outras pessoas.

Além do mais, tornar-se sujeito da própria identidade também é um fator importante, para que os professores desempenhem suas funções de acordo com suas características e especificidades, mas não com base no senso comum, e sim respaldados em um processo de formação profissional que priorize a qualidade do trabalho docente.

\section{REFERÊNCIAS}

BRAGA, Lourdes Aparecida Machado; BEZERRA, Giovani Ferreira; GONÇALVES, Josiane Peres. A(s) identidade(s) do professor de educação infantil: itinerários de formação. Educação Pública, Cuiabá, v. 27, n. 64, p. 41-63, jan./abr. 2018.

BRAGANÇA, Inês Ferreira de Souza. Sobre o conceito de formação na abordagem (auto) biográfica. Educação, Porto Alegre, v. 34, n. 2, p. 157-164, maio/ago. 2011.

DUARTE, Rosália. Entrevistas em pesquisas qualitativas. Educar em Revista, Curitiba, n. 24, p. 213-225, dez. 2004.

FELDEN PEREIRA, Érico; TEIXEIRA, Clarissa Stefani; ANDRADE, Rubian D.; DA SILVA-LOPES, Adair. O trabalho docente e a qualidade de vida dos professores na educação básica. Rev. Salud Pública, Bogotá, v. 16, n. 2, p. 221-231, mar. 2014.

FRASER, Márcia Tourinho; GONDIM, Dantas Sônia Maria Guedes. Da fala do outro ao texto negociado: discussões sobre a entrevista na pesquisa qualitativa. Paidéia, v. 14 n. 28 , 139-152, 2004.

FREIRE, Paulo. Pedagogia da autonomia: saberes necessários à prática educativa. 5. ed. São Paulo: Paz e Terra, 1997.

GONÇALVES, Josiane Peres. O perfil profissional e representações de bem-estar docente e gênero em homens que tiveram carreiras bem-sucedidas no magistério. Orientador: Prof. Dr. Juan José Mouriño Mosquera. 2009. 232 f. Tese (Doutorado em Educação) Pontifícia Universidade Católica do Rio Grande do Sul, PUC/RS, Porto Alegre, 2009.

GUSDORF, Georges. Professores para quê? Para uma pedagogia da pedagogia. 3. ed. São Paulo: Martins Fontes, 2003.

LOURO, Guacira Lopes. Mulheres na Sala de Aula. In: PRIORE, Mary Del; PINSK, Carla Bassanezi. (Orgs.). História das mulheres no Brasil. São Paulo: Contexto, 2012, p. 441-481. 
MOSQUERA, Juan José Mouriño; STOBÄUS, Claus Dieter. Auto-imagem, auto-estima e auto-realização: qualidade de vida na universidade. Psicologia, Saúde \& Doenças, v. 7, n. 1, p. 83-88, 2006.

TARDIF, Maurice. Saberes docentes e formação profissional. 2. ed. Petrópolis: Vozes, 2002.

VEIGA, Ilma Passos Alencastro. A aventura de formar professores. 2. ed. Campinas: Papirus, 2012. (Coleção Magistério Formação e trabalhão Pedagógico).

\section{Como referenciar este artigo}

GONÇALVES, Josiane Peres. "Eu sou professor por decisão, porque eu gosto, porque é minha vida!" Paixão, identidade e formação na docência masculina. Revista IberoAmericana de Estudos em Educação, Araraquara, v. 15, n. 3, p. 1221-1235, jul./set. 2020. e-ISSN: 1982-5587. DOI: https://doi.org/10.21723/riaee.v15i3.12389

Submetido em: 30/09/2019

Revisões requeridas em: 09/10/2019

Aprovado em: 24/10/2019

Publicado em: 20/02/2020 